\title{
Prevalence and correlates of dieting in college women: a cross sectional study
}

This article was published in the following Dove Press journal:

International Journal of Women's Health

10 August 2012

Number of times this article has been viewed

\author{
Flavia Fayet ${ }^{\prime}$ \\ Peter Petocz ${ }^{2}$ \\ Samir Samman' \\ 'Discipline of Nutrition and \\ Metabolism, School of Molecular \\ Bioscience, University of Sydney, \\ ${ }^{2}$ Department of Statistics, Macquarie \\ University, Sydney, NSW, Australia
}

Correspondence: Samir Samman Room 475, Discipline of Nutrition and Metabolism, School of Molecular Bioscience, Building G08, University of Sydney, NSW 2006 Australia

Tel +6I 2 935। 2476

Fax +6I 2 935। 6022

Email samir.samman@sydney.edu.au
Background: Dieting is a common practice among young women, irrespective of age, race, ethnicity, and weight. We aimed to determine the prevalence of dieting and its relationship with eating behavior, body weight, and body mass index (BMI) in college women.

Methods: This was a cross-sectional survey of female students aged $18-35$ years $(n=308)$. Measures included BMI, restraint, disinhibition, hunger, dieting, weight loss, and perceived weight.

Results: A high percentage of college females consider themselves overweight or obese, despite having a BMI in the normal range. Dieting was practised by $43 \%$, and $32 \%$ were avoiding weight gain, despite $78 \%$ having a healthy BMI. Women classified themselves as overweight or obese (27\%), while only $11 \%$ were actually in these categories. Exercise was a common method of weight loss and positive associations were observed between dieting and BMI. Assessment of eating behavior showed that $27 \%$ were classified as high-restraint. Restraint and disinhibition were positively correlated with BMI.

Conclusion: Despite the widespread availability of nutrition information, there is incongruity in measured and perceived BMI in young educated women. Dieting practices and BMI are associated with restraint and disinhibition. Nutrition professionals should consider educating college women about healthy body weight regardless of their clients' BMI.

Keywords: body mass index, college women, dieting, eating behavior

\section{Introduction}

Dieting is a common practice among young women, irrespective of age, race, ethnicity and weight. ${ }^{1-4}$ Studies show that $60 \%-80 \%$ of young students have been on a diet within the previous year ${ }^{5}$ and many have a healthy body mass index (BMI). ${ }^{6}$ Dieting behavior starts at a young age and continues through college where female students have been shown to desire a BMI lower than their current BMI. ${ }^{1,7}$

In the 2000 Behavioral Risk Factor Surveillance System, a telephone survey of American adults, a higher percentage of women than men reported trying to lose weight, with women reporting trying to lose weight at a lower BMI than men. ${ }^{2}$ Results from the National Health Interview Survey of US Adults showed that $38 \%$ of women were trying to lose weight. Attempting weight loss was common also among women $(24 \%)$ with a normal BMI. ${ }^{3}$

Dieting may contribute to poor mental and physical health, ${ }^{8}$ and a BMI under $17.5 \mathrm{~kg} / \mathrm{m}^{2}$ exposes individuals to higher risks of nutrient deficiencies and lower fertility. ${ }^{9}$ Dieting is often a precursor to an eating disorder (ED), as a higher percentage of women who regularly diet report problems in eating behavior than those with 
no previous dieting experience. ${ }^{10,11}$ Not all individuals meet the diagnostic criteria for ED, ${ }^{12}$ but develop disorderedeating behaviors. ${ }^{13}$ Overestimation of body fatness and dieting are reported to be proportional to the prevalence of eating disorders. ${ }^{14}$

Various studies have shown that the freshman year of college is associated with weight gain..$^{15,16}$ The transition to a university provides an environment with new pressures and workload, anxiety and stress, increased sense of independence, and a change in routine that can affect diet and exercise patterns. ${ }^{1}$ Dietary practices such as consuming breakfast and sweetened beverages have a significant impact on body weight. In a cross-sectional study in adolescent girls, those who consumed breakfast more frequently were more likely to have a lower BMI and lower percentage of body fat compared to those consuming breakfast less frequently. In contrast, girls who consumed sugar-sweetened beverages more frequently were more likely to have a higher BMI and percent body fat compared to females who did not. ${ }^{4}$

College offers an opportunity for promoting healthy eating and exercise habits and long-term weight management in the adult population. By understanding the factors associated with dieting, eating behavior, and weight management, more effective public health messages can be used to promote healthy eating. Therefore, the aim of this study was to determine the prevalence of dieting and describe the relationship with eating behavior and weight status in a sample of college women.

\section{Methods}

\section{Subjects}

A total of 308 female students, aged 18-35 years, were recruited from the university campus using flyers, wordof-mouth referrals, and University publications. Participants with diagnosed ED, pregnant or breastfeeding students, and elite athletes (eg, members of representative sports teams) were excluded from the study. All participants were fluent English-speakers. The institutional Human Ethics Committee granted approval and all participants provided written consent.

\section{Procedures}

Potential participants communicated with the researchers initially by email or by telephone and provided some personal information including their weight and height. Meetings were arranged with participants who met the inclusion criteria. A trained and experienced anthropometrist measured height to the nearest $0.1 \mathrm{~cm}$ (Bodymeter Measuring Tape; Seca 206, Birmingham, UK) and weight to the nearest $0.5 \mathrm{~kg}$ using a bioelectrical impedance analysis scale (UM-020; Tanita Corporation, Arlington Heights, IL). The values obtained were used to calculate the BMI. Participants were classified in BMI categories according to the World Health Organization criteria. $^{17}$

\section{Measures}

Eating behavior was assessed using an electronic version of the Eating Inventory (EI; formerly Three-Factor Eating Questionnaire), ${ }^{18}$ a 51-item questionnaire containing three dimensions of eating behavior: restraint, disinhibition, and hunger. Restraint measures an individual's tendency to restrict food intake in order to lose weight or to prevent weight gain. Disinhibition measures the tendency to overeat, and the third factor measures the degree of perceived hunger.

The restraint scale ranges from 0 (no restraint) to 21 (high restraint). The disinhibition scale is scored from 0 (no disinhibition) to 16 (high disinhibition), and the hunger scale is scored from 0 (no hunger) to 14 (high hunger). ${ }^{18}$ The median split is commonly used as the cut-off to identify individuals in the categories of low versus high. Responses to restraint questions were evaluated further to identify 2 subcategories of restraint: rigid or flexible control. ${ }^{19}$ These subcategories refer to approaches to eating and dieting that are "all-or-nothing" (rigid) or a "gradual" (flexible) attitude that incorporates all foods in smaller amounts rather than restricting entire food groups. For example, flexible control allows for "fattening" foods to be eaten in limited quantities without feelings of guilt. ${ }^{19}$

Participants were asked to respond to questions related to self-perception of their weight, weight change over the past year, weight loss attempts during the 3 months preceding their participation in the present study, methods of active weight control, and weight stability. The questionnaires were emailed to participants and they were asked to return the completed questions via email within 2 weeks of anthropometric measurements. All participants received a unique code for deidentification purposes.

\section{Data analysis}

Statistical analyses were carried out using the Statistical Package for the Social Sciences (SPSS Macintosh v 16; SPSS Inc, Chicago, IL). Values for body weight perception, weight-loss methods, and dieting status were calculated based on simple frequency. Values for age, weight, height, BMI, and dieting behavior scores (restraint, disinhibition, hunger) 
are expressed as the mean $\pm \mathrm{SD}$. Analysis of variance was used to compare mean scores on eating behavior scales, dieting scales, and BMI. The Chi-square test was used to evaluate differences between categorical variables (such as dieting status and BMI). Statistical significance was set at $P<0.05$.

\section{Results}

\section{Participant characteristics}

The participants' ages and BMI were $22.6 \pm 3.6$ years and $21.5 \pm 2.8 \mathrm{~kg} / \mathrm{m}^{2}$, respectively. All were currently enrolled college students in a range of faculties. The response rate for those who completed the EI was $89 \%(n=275)$, of which $\mathrm{n}=263$ responded to dieting questions. No significant differences in anthropometric measures were found between nonrespondents and respondents of the EI. The mean scores for restraint, disinhibition, and hunger were 8.2 $\pm 5.2,6.5 \pm 3.4$, and $5.2 \pm 3.1$, respectively. Based on the median cut-off values, $57 \%$ were classified as restrained, $44 \%$ were classified as disinhibited, and 56.4\% were classified as hungry (Table 1). Mean rigid and flexible restraint scores were $2.3 \pm 1.9$ and $3.0 \pm 1.9$, respectively.

\section{$\mathrm{BMI}$ and dieting practices}

Overall restraint scores and rigid restraint scores were positively correlated with BMI $(\mathrm{r}=0.25, P<0.001 ; \mathrm{r}=0.20$, $P<0.01)$, respectively. Disinhibition scores were positively correlated to weight $(\mathrm{r}=0.23, P<0.001)$ and BMI (r=0.23, $P<0.001)$. Compared to women in the lower median split, those who were in the upper median split of disinhibition had significantly higher scores for rigid restraint $(P<0.0001)$. As BMI increased, disinhibition and rigid restraint scores increased significantly $(P<0.01)$, but flexible restraint did not increase (Figure 1). No association was found between flexible restraint score, BMI, and disinhibition.
Participants in the study generally overestimated their BMI (Table 2). While 10.6\% were underweight $\left(\mathrm{BMI}<18.5 \mathrm{~kg} / \mathrm{m}^{2}\right.$ ), only $4.6 \%$ classified themselves as very underweight or slightly underweight; $78.0 \%$ were normal weight $(\mathrm{BMI}=18.5-24.9)$, while $65 \%$ classified themselves as "about the right weight" and $11.4 \%$ were overweight or obese (BMI $\geq 25$, with $1 \%$ obese BMI $\geq 30$ ), while $27.3 \%$ classified themselves as slightly overweight or very overweight.

Compared to the previous year, $25.1 \%$ did not weigh themselves and did not know their weight, while $1.9 \%$ could not remember. BMI was significantly higher in women who reported their weight to have increased in comparison to those whose BMI remained the same (Table 3 ). In addition, weight was significantly higher $(P<0.05)$ in women whose weight increased and in those who stated that they did not remember.

A large proportion of participants were either actively trying to lose weight $(43.3 \%)$ or avoid weight gain $(32.3 \%)$, while $20.5 \%$ were not doing anything to change their weight and $3.8 \%$ were trying to gain weight. Of the women trying to lose weight, most $(81.5 \%)$ were within the healthy weight range. Overweight or obese women were actively trying to lose weight $(73 \%, n=22)$ and $50 \%(n=14)$ of underweight women were trying to avoid weight gain or actively trying to lose weight. Weight loss attempts in the 3 months preceding the study were reported by $30.8 \%$ of the participants $(n=81)$, while $62 \%$ $(\mathrm{n}=162)$ did not try to lose weight and $7.6 \%(\mathrm{n}=20)$ were unsure. Despite the misclassification of body weight among the women, those who classified themselves in the lower weight categories had a lower mean BMI that progressively increased for each increase in perceived weight category, and differed significantly from each other. Mean BMI values increased as the category of dieting increased from "gaining weight," "not relevant," "avoiding weight gain," and "losing weight".

Table I Distribution of eating behavior scores and physical characteristics of study participants

\begin{tabular}{|c|c|c|c|c|c|}
\hline Eating behavior & $\%$ & Age (y) & Height (m) & Weight (kg) & BMI $\left(\mathrm{kg} / \mathrm{m}^{2}\right)$ \\
\hline \multicolumn{6}{|l|}{ Restraint } \\
\hline Unrestrained (157) & 42.9 & $22.6 \pm 4.1$ & $1.65 \pm 0.07$ & $58.1 \pm 8.5$ & $21.2 \pm 2.5$ \\
\hline Restrained $(n=1 \mid 8)$ & 57.1 & $22.4 \pm 3.5$ & $1.65 \pm 0.07$ & $59.2 \pm 9.1$ & $21.4 \pm 2.6$ \\
\hline \multicolumn{6}{|l|}{ Disinhibition } \\
\hline Nondisinhibited $(n=154)$ & 56.0 & $22.9 \pm 4.1$ & $1.65 \pm 0.07$ & $57.1 \pm 8.1^{\mathrm{a}}$ & $21.1 \pm 2.5^{b}$ \\
\hline Disinhibited $(n=121)$ & 44.0 & $22.1 \pm 3.4$ & $1.66 \pm 0.07$ & $60.5 \pm 9.3^{\mathrm{a}}$ & $21.9 \pm 2.6^{b}$ \\
\hline \multicolumn{6}{|l|}{ Hunger } \\
\hline Low hunger $(n=155)$ & 56.4 & $22.6 \pm 4.1$ & $1.64 \pm 0.06^{\mathrm{a}}$ & $57.9 \pm 8.1$ & $21.5 \pm 2.4$ \\
\hline Hungry $(n=120)$ & 43.6 & $22.5 \pm 3.5$ & $1.66 \pm 0.08^{\mathrm{a}}$ & $53.0 \pm 4.3$ & $21.5 \pm 2.9$ \\
\hline
\end{tabular}

Notes: Values for restraint, disinhibition, and hunger are expressed as arbitrary units. Data are shown as the median split. Shared superscripts within the same column are significantly different; $P<0.05$. Abbreviation: BMI, body mass index. 


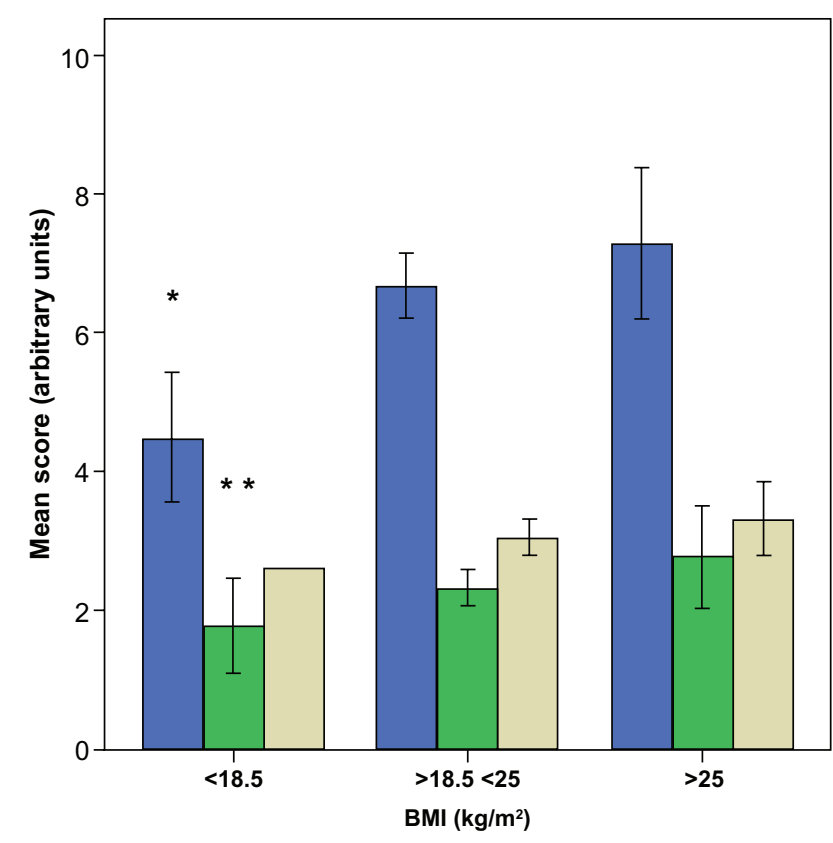

Figure I Mean scores for disinhibition and rigid and flexible restraint by BMI category $(n=275)$.

Notes: Scores for disinhibition $(\square)$, rigid $(\square)$ and flexible restraint $(\square)$. Disinhibition and Rigid scores increase with increasing BMI category. Trend is statistically significant. $* P<0.001$; $* * P<0.05$.

Abbreviation: $\mathrm{BMI}$, body mass index.

Exercise as a method of weight loss was reported by $30.8 \%$ of women, participation in organized programs was reported by $1.9 \%$, meal replacements by $0.4 \%$, and non-specified methods by $11.8 \%$. When methods of weight loss were compared with BMI category (Table 3), 33\% of women with normal weight reported using exercise, while $40 \%$ of overweight or obese women reported using exercise. Women who used organized programs had a healthy BMI $(P<0.05)$.

\section{Relationships between El and BMI}

Restraint and disinhibition scores increased as self-assessed weight category increased (Table 3). Restraint scores were lowest in women who did not remember if their weight changed since the previous year and highest in those who lost weight. Both disinhibition and hunger scores were higher in women who reported their weight to have increased. Methods of weight loss reported as exercise, organized programs, or "other" were associated with higher restraint scores than in women who did not use weight loss methods $(P<0.05)$. Current dieting was related to eating behavior scores (Table 3). The lowest restraint was found in nondieters and the lowest disinhibition scores in women trying to gain weight. In contrast, the highest scores for restraint and disinhibition were reported by women actively trying to lose weight.

\section{Discussion}

The findings from the present study show that $24 \%$ of college females misclassified their BMI and considered themselves as overweight, despite being of normal weight. A positive relationship was identified between restrained eating and dieting as well as between disinhibition and body weight. The results of our survey suggest that dieting practices are associated with BMI and that restrained eating and disinhibition are factors related to BMI.

Dieting irrespective of BMI has been previously reported, and $13.2 \%$ of normal weight female students were currently dieting to lose weight. ${ }^{20}$ Similarly, other studies have shown that one in five normal-weight women attempt to lose weight; normal-weight women attempting to lose weight had higher BMIs than those who were not dieting. ${ }^{21}$ In the present study, many women who had healthy BMIs were currently trying to lose weight.

The correlation between amount of desired weight loss and BMI observed in the present study has been previously reported among young women. ${ }^{22}$ Other reports ${ }^{23,24}$ have shown an inverse correlation between BMI and satisfaction with body weight. Body dissatisfaction may lead to dieting practices in young women, which may have long-term consequences if nutrient needs are not met.

Restraint scores increased as perceived weight status increased. Dieters had both higher restraint and higher disinhibition scores than nondieters. It has been suggested that disinhibition may be more significant in identifying adverse health effects of dieting than restraint..$^{5}$ The understanding of eating behavior in young adults is important as it is a predictor of weight gain in adulthood, with both restraint and disinhibition behaviors being associated with adult weight gain..$^{25,26}$

In a heterogeneous population ranging from underweight to obese women, Timko and Perone ${ }^{27}$ investigated rigid and flexible control of eating behaviors and their relationships to body weight. They found that rigid control was positively associated with BMI, an observation that was also observed in the present study. However, unlike the present findings, Timko and Perone ${ }^{27}$ reported that flexible restraint was inversely associated with BMI and disinhibition. Flexible control was not found to be associated with favorable health outcomes such as less eating and emotional pathology, but rather to have no relationship to the numerous variables assessed in the study. Rigid restraint behavior has been implicated in low dieting success, while flexible control is often associated with successful weight loss. In an online survey, Meule et $\mathrm{a}^{28}$ confirmed this observation and demonstrated 
Table 2 Dieting behavior categorized by age, height, body weight, and BMI

\begin{tabular}{|c|c|c|c|c|}
\hline Question & BMI & Restraint & Disinhibition & Hunger \\
\hline \multicolumn{5}{|l|}{ Do you consider yourself to be } \\
\hline Very underweight $(n=4)$ & $17.7 \pm 0.6^{*}$ & $5.5 \pm 2.4^{*}$ & $4.5 \pm 1.9 *$ & $5.8 \pm 5.2$ \\
\hline Slightly underweight $(\mathrm{n}=18)$ & $18.6 \pm 1.2$ & $5.1 \pm 3.9$ & $4.5 \pm 2.5$ & $6.2 \pm 3.3$ \\
\hline About the right weight $(n=169)$ & $21.1 \pm 2.1$ & $8.3 \pm 5.1$ & $6.2 \pm 3.3$ & $5.1 \pm 3.0$ \\
\hline Slightly overweight $(\mathrm{n}=68)$ & $23.2 \pm 2.5$ & $9.0 \pm 5.4$ & $7.8 \pm 3.4$ & $5.1 \pm 3.3$ \\
\hline Very overweight $(n=4)$ & $25.9 \pm 6.5$ & $12.0 \pm 3.2$ & $9.5 \pm 3.7$ & $5.8 \pm 1.0$ \\
\hline \multicolumn{5}{|l|}{ Compared to last year has your weight } \\
\hline Increased $(n=60)$ & $22.3 \pm 2.9^{\mathrm{a}}$ & $8.4 \pm 4.8^{d}$ & $8.3 \pm 3.7^{\mathrm{a}}$ & $6.1 \pm 3.2$ \\
\hline Decreased $(n=45)$ & $21.8 \pm 2.6$ & $11.0 \pm 5.7^{c}$ & $6.2 \pm 3.7$ & $4.3 \pm 3.1$ \\
\hline Stayed the same $(n=87)$ & $20.9 \pm 2.4^{\mathrm{a}}$ & $7.6 \pm 5.0^{\mathrm{d}}$ & $5.8 \pm 3.0^{\mathrm{b}}$ & $5.3 \pm 3.2$ \\
\hline Don't know, I don't weigh myself $(n=66)$ & $21.2 \pm 2.4$ & $7.6 \pm 5.0^{d}$ & $6.2 \pm 3.0$ & $5.0 \pm 2.8$ \\
\hline Don't remember $(n=5)$ & $21.6 \pm 2.0$ & $4.8 \pm 3.1$ & $6.4 \pm 1.1$ & $3.8 \pm 2.7$ \\
\hline \multicolumn{5}{|l|}{ Have you tried to lose weight in the past 3 months? } \\
\hline Yes $(n=8 I)$ & $22.3 \pm 2.7^{*}$ & $10.9 \pm 5.2$ & $7.9 \pm 3.6$ & $5.5 \pm 3.2$ \\
\hline No $(n=162)$ & $21.0 \pm 2.4$ & $7.0 \pm 4.6$ & $5.9 \pm 3.1$ & $5.1 \pm 3.1$ \\
\hline Not sure $(n=20)$ & $22.3 \pm 2.3$ & $8.3 \pm 5.1$ & $6.7 \pm 2.5$ & $4.8 \pm 2.8$ \\
\hline \multicolumn{5}{|c|}{ If you tried to lose weight in the past 3 months, what methods did you use? } \\
\hline Exercise $(n=8 I)$ & $22.3 \pm 2.6^{* *}$ & $9.9 \pm 5.1$ & $7.3 \pm 3.7$ & $5.4 \pm 2.9$ \\
\hline Organized programs $(n=5)$ & $22.4 \pm 2.2$ & $9.0 \pm 7.2$ & $7.2 \pm 3.4$ & $5.6 \pm 5.2$ \\
\hline Meal replacements $(n=1)$ & 20.8 & 11.0 & 10.0 & 9.0 \\
\hline Have not tried to lose weight $(n=145)$ & $21.0 \pm 2.5$ & $6.9 \pm 4.8$ & $5.6 \pm 3.0$ & $5.0 \pm 3.1$ \\
\hline Other $(n=3 I)$ & $21.7 \pm 2.5$ & $10.5 \pm 5.0$ & $8.4 \pm 3.2$ & $5.2 \pm 3.2$ \\
\hline \multicolumn{5}{|l|}{ I am actively trying to } \\
\hline Gain weight $(n=9)$ & $18.5 \pm 1.5^{*}$ & $3.9 \pm 2.5$ & $3.3 \pm 1.9$ & $6.4 \pm 4.7$ \\
\hline Not relevant; not doing anything to change my weight $(n=54)$ & $20.8 \pm 2.1$ & $5.2 \pm 4.1$ & $5.3 \pm 3.3$ & $4.5 \pm 3.1$ \\
\hline Avoid gaining weight $(n=85)$ & $21.3 \pm 2.2$ & $8.9 \pm 5.1$ & $6.6 \pm 3.2$ & $5.4 \pm 2.8$ \\
\hline Lose weight $(n=112)$ & $22.3 \pm 2.8$ & $9.7 \pm 5.1$ & $7.4 \pm 3.3$ & $5.3 \pm 3.1$ \\
\hline
\end{tabular}

Notes: Data are shown as the mean $\pm S D, n=263$. Trends within a column are significant; $* P<0.00$ I; $* * P<0.0$ I. Shared superscripts within the same column are statistically significant; ${ }^{a, b} P<0.05$; ${ }^{c, d} P<0.01$.

Abbreviation: BMI, body mass index.

that experiencing food cravings mediated the relationship between rigid restraint and dieting success. In contrast, flexible restraint predicted dieting success independently of food cravings. The relationships between rigid and flexible control to BMI require further clarification.

Exercise as a method of weight loss was reported by a high percentage of women in the present study. Similar strategies in addition to eating fewer calories, particularly from dietary fat, have been reported previously. ${ }^{4,29}$ Despite the awareness of diet and exercise, results from the National Health and Nutrition Examination Survey showed that most people who attempt weight loss (or weight control) do not use recommended combinations of energy restriction and adequate levels of physical activity. ${ }^{29}$

There is debate regarding the effectiveness of the EI in terms of both its conceptual and psychometric capacities. ${ }^{30-33}$ Heatherton et $\mathrm{al}^{30}$ evaluated the restraint scale and concluded that it is a useful tool for examining behavioral and other differences between dieters and nondieters. It has been argued, however, that restraint scores cannot be used to differentiate between inhibition and disinhibition because of intraindividual variations in food intake and behaviors such as binging and the inability of the instrument to differentiate between dieters' attitudes toward failure of restraint. ${ }^{31}$ Lowe et a ${ }^{32}$ used data from food records, questionnaires, and interviews to test the continuum model of bulimia nervosa. The model suggested that dieting is associated with psychological features of bulimia nervosa, although this did not extend to eating behaviors and symptoms. Whether dietary restraint scales are related to dietary intake was investigated by Stice et al. ${ }^{33}$ In a re-evaluation of three studies, it was shown that restraint scales did not correlate with objective measures of caloric intake. The authors suggest that restraint scales may be used to assess relative rather than absolute dietary restriction; that is, individuals with elevated restraint scores may be eating less than they desire and thus may perceive this behavior as dietary restraint even if they are not achieving the desired weight loss. The observation in the present study that restraint scores were related to BMI warrants further investigation.

Limitations of our study include the convenience sampling and the cross-sectional nature of this study, which may have attracted female college students who are particularly interested 
Table 3 Prevalence of dieting behaviors in different BMI categories ${ }^{\mathrm{a}, \mathrm{b}}$

\begin{tabular}{|c|c|c|c|}
\hline & \multicolumn{3}{|c|}{ BMI $\left(\mathrm{kg} / \mathrm{m}^{2}\right)$ category } \\
\hline & $<18.5 \mathrm{n}=\mathbf{2 8}$ & $18.5-25 n=205$ & $\geq \mathbf{2 5} \mathbf{n}=\mathbf{3 0}$ \\
\hline \multicolumn{4}{|c|}{ Have you tried to lose weight in the 3 months preceding your participation in this survey? } \\
\hline Yes $(n=8 I, 30.8 \%)$ & 2 & 66 & $13 *$ \\
\hline No $(n=162,61.6 \%)$ & 26 & 123 & 13 \\
\hline Not sure $(n=20,7.6 \%)$ & 0 & 16 & 4 \\
\hline \multicolumn{4}{|l|}{ Compared to last year at this time, has your weight } \\
\hline Increased $(n=60,22.8 \%)$ & 3 & 48 & 9 \\
\hline Decreased $(n=45,17.1 \%)$ & 4 & 31 & 10 \\
\hline Same $(n=87,33.1 \%)$ & 12 & 70 & 5 \\
\hline Don't know, I don't weigh myself $(n=66,25.1 \%)$ & 9 & 51 & 6 \\
\hline Don't remember $(n=5,1.9 \%)$ & 0 & 5 & 0 \\
\hline \multicolumn{4}{|l|}{ Do you consider yourself } \\
\hline Very underweight $(n=4,1.5 \%)$ & 4 & 0 & 0 \\
\hline Slightly underweight $(n=18,6.8 \%)$ & 9 & 9 & 0 \\
\hline About the right weight $(n=169,64.3 \%)$ & 15 & 146 & 8 \\
\hline Slightly overweight $(n=68,25.9 \%)$ & 0 & 48 & 20 \\
\hline Very overweight $(n=4,1.5 \%)$ & 0 & 2 & 2 \\
\hline \multicolumn{4}{|c|}{ If you tried to lose weight in the past 3 months, which methods have you used? } \\
\hline Exercise $(n=8 I, 30.8 \%)$ & 2 & 67 & 12 \\
\hline Organized programs $(n=5,1.9 \%)$ & 0 & 4 & 1 \\
\hline Meal replacements $(\mathrm{n}=\mathrm{I}, 0.4 \%)$ & 0 & 1 & 0 \\
\hline Have not tried to lose weight $(n=145,55.1 \%)$ & 26 & 106 & 13 \\
\hline Other $(n=31,11.8 \%)$ & 0 & 27 & 4 \\
\hline \multicolumn{4}{|l|}{ I am actively trying to } \\
\hline Gain weight $(n=10,3.8 \%)$ & 6 & 4 & 0 \\
\hline Avoid gaining weight $(n=85,32.3 \%)$ & 7 & 73 & 5 \\
\hline Lose weight $(n=114,43.3 \%)$ & 7 & 85 & 22 \\
\hline Not relevant; not doing anything to change my weight $(n=54,20.5 \%)$ & 8 & 43 & 3 \\
\hline
\end{tabular}

Notes: ${ }^{a} \mathrm{BMI}$ categories based on $\mathrm{WHO}$ classification; ${ }^{17}$ bdata are shown for $\mathrm{n}=263$. Trend significant. $* \mathrm{p}<0.05$. Abbreviations: BMI, body mass index; WHO, World Health Organization.

in health and dieting, or those who are prone to disordered eating behaviors. Another limitation is the restricted geographic scope, having recruited students from a single campus in one region of the country. As reasons for dieting were not accessed, the driving force for such behaviors in this population could not be determined. Despite nonrespondents having similar BMI to respondents, eating behavior patterns may have been different. The strengths of the study include an adequate sample size that has allowed for the calculation of prevalence of dieting and related behavior. Our survey has highlighted associations that can be investigated in future studies.

Young women are under social pressure to maintain a low BMI and have therefore developed an altered perception of what constitutes a healthy BMI. ${ }^{34}$ The results of the present study reveal that there is incongruity in the selfperception of college women regarding body weight status. Nutrition professionals should consider educating college women about body weight regardless of their clients' measured BMI. Attention should be focused on the behavioral aspects of food when assessing the nutritional status of college women.

\section{Acknowledgments/disclosure}

The authors thank the study volunteers for their participation and cooperation with the study. The authors confirm that no competing financial interests exist. The study was supported financially by Meat and Livestock Australia Human Nutrition R\&D grant (MLA-CMHN-050).

\section{References}

1. Malinauskas BM, Raedeke TD, Aeby VG, Smith JL, Dallas MB. Dieting practices, weight perceptions, and body composition: a comparison of normal weight, overweight, and obese college females. Nutr J. 2006;5:1-8.

2. Bish CL, Blanck HM, Serdula MK, Marcus M, Kohl HW 3rd, Khan LK. Diet and physical activity behaviors among Americans trying to lose weight: 2000 Behavioral Risk Factor Surveillance System. Obes Res. 2005;13:596-607.

3. Kruger J, Galuska DA, Serdula MK, Jones DA. Attempting to lose weight: specific practices among US adults. Am J Prev Med. 2004;26: 402-406. 
4. Laska MN, Murray DM, Lytle LA, Harnack LJ. Longitudinal associations between key dietary behaviors and weight gain over time: transitions through the adolescent years. Obesity. 2012;20:118-125.

5. Fonseca H, Matos MG, Guerra A, Pedro JG. Are overweight adolescents at higher risk of engaging in unhealthy weight-control behaviors? Acta Paediatr. 2009;98:847-852.

6. Ackard DM, Croll JK, Kearney-Cooke A. Dieting frequency among college females: Association with disordered eating, body image, and related psychological problems. J Psychosom Res. 2002;52:129-136.

7. Wong YI, Huang YC. Obesity concerns, weight satisfaction and characteristics of female dieters: a study on female Taiwanese college students. J Am Coll Nutr. 1999;18:194-200.

8. French SA, Jeffery RW. Consequences of dieting to lose weight: effects on physical and mental health. Hlth Psych. 1994;13:195-212.

9. Grodstein F, Goldman MB, Cramer DW. Body mass index and ovulatory infertility. Epidemiology. 1994;5:247-250.

10. King MB. Eating disorders in a general practice population. Prevalence, characteristics and follow-up at 12 to 18 months. Psych Med. 1989; $14: 1-34$

11. Westenhoefer J, Pudel V. Pleasure from food: importance for food choice and consequences of deliberate restriction. Appetite. 1993; 20:246-249.

12. Becker AE, Eddy KT, Perloe A. Clarifying criteria for cognitive signs and symptoms for eating disorders in DSM-V. Int J Eat Disord. 2009; 42:611-619.

13. Hay PJ, Fairburn CG, Doll HA. The classification of bulimic eating disorders: a community-based cluster analysis study. Psych Med. 1996;26:801-812.

14. Hill AJ, Bhatti R. Body shape perception and dieting in preadolescent British Asian girls: links with eating disorders. Int J Eat Dis. 1995; 17:175-183.

15. Delinsky SS, Wilson GT. Weight gain, dietary restraint, and disordered eating in the freshman year of college. Eat Behav. 2008;9:82-90.

16. Anderson DA, Shapiro JR, Lundgren JD. The freshman year of college as a critical period for weight gain: an initial evaluation. Eat Behav. 2003;4:363-367.

17. World Health Organization (2000). Obesity: preventing and managing the global epidemic. Geneva: World Health Organization. http://apps. who.int/bmi/index.jsp?introPage=intro_3.html. Accessed 16 May 2012.

18. Stunkard AJ, Messick S. The three-factor eating questionnaire to measure dietary restraint, disinhibition and hunger. J Psychosom Res. 1985;29:71-83.

19. Westenhoefer J. Dietary restraint and disinhibition: is restraint a homogeneous construct? Appetite. 1991;16:45-55.
20. Jaworowska A, Bazylak G. An outbreak of body weight dissatisfaction associated with self-perceived BMI and dieting among female pharmacy students. Biomed Pharmacother. 2009;63:679-692.

21. Wardle J, Johnson F. Weight and dieting: examining levels of weight concern in British adults. Int J Obes Rel Met Dis. 2002;26:1144-1149.

22. Drewnowski A, Hann C. Food preferences and reported frequencies of food consumption as predictors of current diet in young women. $\mathrm{Am} \mathrm{J}$ Clin Nutr. 1999;70:28-36.

23. Lattimore P. Body dissatisfaction in females varies according to deprivation state and is modified by weight rather than restraint status. Appetite. 2005;45:356-359.

24. Heatherton TF, Mahamedi F, Striepe M, Field AE, Keel P. A 10-year longitudinal study of body weight, dieting, and eating disorder symptoms. J Abnorm Psychol. 1997;106:117-125.

25. Hays NP, Bathalon GP, McCrory MA, Roubenoff R, Lipman R, Roberts SB. Eating behavior correlates of adult weight gain and obesity in healthy women aged 55-65 y. Am J Clin Nutr. 2002;75:476-483.

26. Bellisle F, Clement K, Le Barzic M, Le Gall A, Guy-Grand B, BasdevantA. The Eating Inventory and body adiposity from leanness to massive obesity: a study of 2509 adults. Obes Res. 2004;12:2023-2030.

27. Timko CA, Perone J. Rigid and flexible control of eating behavior in a college population. Eat Behav. 2005;6:119-125.

28. Meule A, Westenhöfer J, Kübler A. Food cravings mediate the relationship between rigid, but not flexible control of eating behavior and dieting success. Appetite. 2011;57:582-584.

29. Weiss EC, Galuska DA, Khan LK, Serdula MK. Weight-control practices among US adults, 2001-2002. Am J Prev Med. 2006;31:18-24.

30. Heatherton TF, Herman CP, Polivy J, King GA, McGree ST. The (mis) measurement of restraint: an analysis of conceptual and psychometric issues. J Abnorm Psychol. 1988;97:19-28.

31. van Strien T. Success and failure in the measurement of restraint: notes and data. Int J Eat Disord. 1999;25:441-449.

32. Lowe MR, Gleaves DH, DiSimone-Weiss RT, et al. Restraint, dieting, and the continuum model of bulimia nervosa. J Abnorm Psychol. 1996;105:508-517.

33. Stice E, Sysko R, Roberto CA, Allison S. Are dietary restraint scales valid measures of dietary restriction? Additional objective behavioral and biological data suggest not. Appetite. 2010;54:331-339.

34. Lopez-Guimera G, Levine LP, Sanchez-Carracedo D, Fauquet J. Influence of mass media on body image and eating disordered attitudes and behaviors in females: a review of effects and process. Media Psychol. 2010;13:387-416.
International Journal of Women's Health

\section{Publish your work in this journal}

The International Journal of Women's Health is an international, peerreviewed open-access journal publishing original research, reports, reviews and commentaries on all aspects of women's healthcare including gynecology, obstetrics, and breast cancer. Subject areas include: Chronic conditions (migraine headaches, arthritis, osteoporosis);

\section{Dovepress}

Endocrine and autoimmune syndromes; Sexual and reproductive health; Psychological and psychosocial conditions. The manuscript management system is completely online and includes a very quick and fair peer-review system. Visit http://www.dovepress.com/ testimonials.php to read real quotes from published authors. 